\title{
INVESTIGATION OF THE LOSS OF BONE MINERAL IN PATIENTS WITH SPINAL CORD INJURY
}

\author{
By Harry J. Griffiths, M.D., Boris BushuefF, M.D. and \\ ROBERT E. ZimMERMAN, M.S.E.E. \\ Departments of Radiology at Harvard Medical School, Peter Bent Brigham Hospital, and \\ West Roxbury Veterans Administration Hospital, Boston, Mass., U.S.A.
}

Abstract. Thirty-six (36) spinal cord injury patients (22 tetraplegic andr4 paraplegic) had hand radiographs taken in association with bone density measurements. The cortical bone of the hand, the radius, and the ulna was found to be normal, but there was an obvious decrease in the amount of trabecular bone. There were three predominant radiographic patterns of osteopenia - generalised, juxta-articular, and cystic. The cause of this decrease in trabecular bone is not understood, although it may be related to alterations in blood flow.

Key words: Density measurements, osteopenia.

IN a previous communication, the use of photon absorptiometry in a group of patients with spinal cord injury was described (Griffiths et al., 1972). The cortical bone was found to be normal, but radiographs of the hands revealed apparent loss of trabecular bone. Details of further investigation into this finding are given here.

\section{Material and Methods}

Thirty-six patients were scanned on a Norland Cameron osteodensitometer (Zimmerman et al., I973): 22 were quadriplegic and I4 were paraplegic. Each patient was scanned across the lower arm at the wrist for trabecular bone and onethird of the way up the arm for cortical bone. Radiographs of the lower arm were available on 25 patients and read blindly by two of us (H. J. G. and B. B.) on two separate occasions. The group of paired normals has been described (Griffiths et al., 1972).

\section{Results}

No significant difference could be shown between the bone mineral measurements of cortical bone at the lower radius and ulna in normals and in those patients with spinal cord injury (Table I). The measurement of radiographic metacarpal index and clavicular index were also within normal limits.

There was a decrease in the trabecular bone mineral of the lower radius in all of the patients $(<0.995)$ although in some patients it was more marked than in others (fig. I). If allowance is made for the fact that the distal end of the radius is wider than the midshaft of the bone, this loss of bone mineral becomes more marked.

The loss of trabecular bone was confirmed by the radiographs (figs. 2-4) and only one of the 25 radiographs of the wrist were considered to show normal bone. There was a trend toward the quadriplegic patient having more marked loss of 


\section{TABLE I}

Comparison of cortical bone mineral mass in spinal cord injury patients and in matched normal controls

\begin{tabular}{|c|c|c|c|c|c|}
\hline Group & $\begin{array}{l}\text { Mean } \\
\text { age }\end{array}$ & $\begin{array}{l}\text { Number } \\
\text { pts }\end{array}$ & $\begin{array}{c}\text { Mean } \\
\text { B.M.U. }\end{array}$ & Slope & $\begin{array}{l}\text { Standard } \\
\text { error }\end{array}$ \\
\hline \multicolumn{6}{|c|}{ Age range $20-55$} \\
\hline Normals & $35 \cdot 36$ & 95 & $23 \cdot 33$ & 0.0293 & 0.0339 \\
\hline Injured & $37 \cdot 52$ & $7 I$ & $23 \cdot 18$ & 0.03652 & 0.0529 \\
\hline \multicolumn{6}{|c|}{ Age range 56 and above } \\
\hline Normals & 63.00 & 19 & $22 \cdot 90$ & -0.1390 & 0.156 \\
\hline Injured & $6 I \cdot 8 I$ & I6 & $23 \cdot 21$ & -0.1162 & 0.221 \\
\hline
\end{tabular}

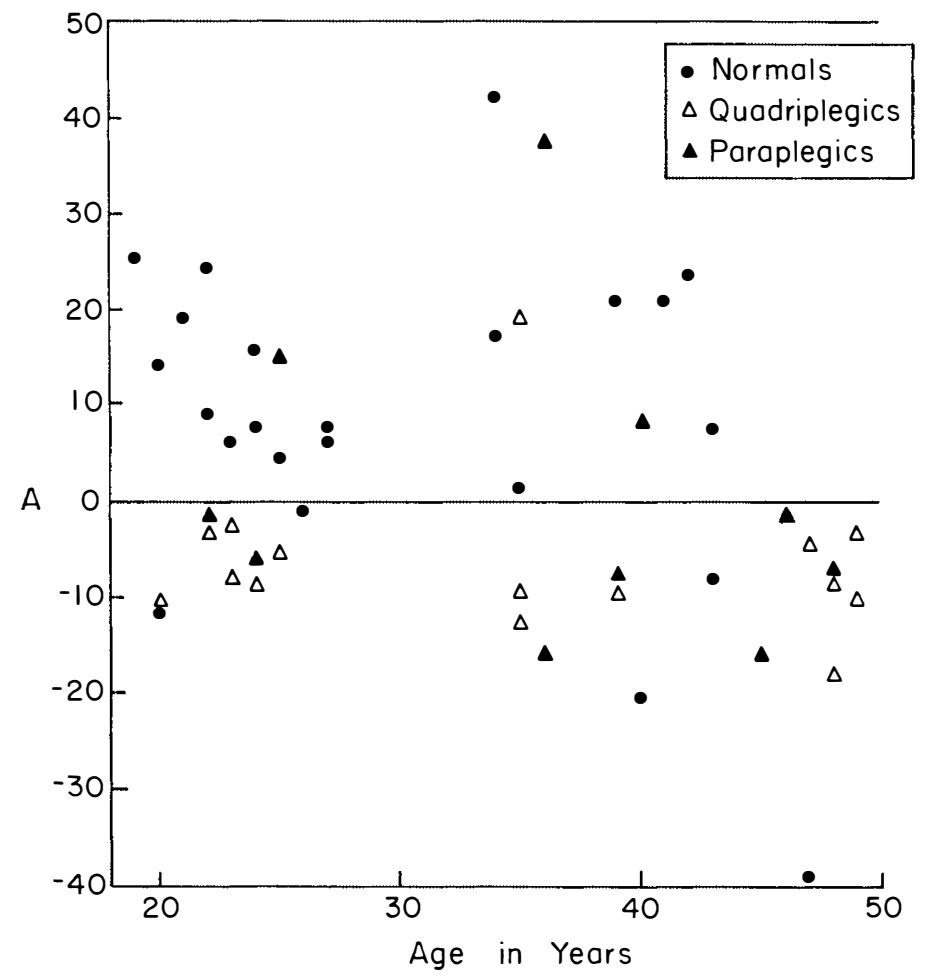

Fig. I

Graph of the difference between cortical and trabecular bone mineral mass in a group of 25 patients with spinal cord injury in comparison to 23 matched normal controls. 


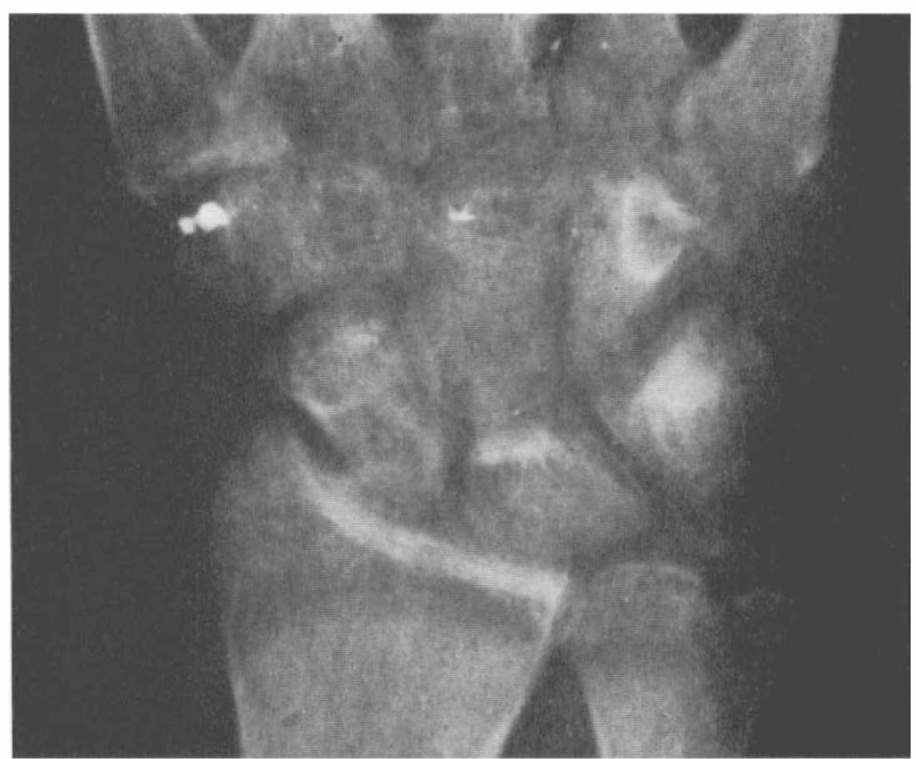

FIG. 2

Loss of trabecular bone in a quadriplegic patient aged 24. The appearances are very similar to an early disuse osteoporosis, although this patient had been paralysed for 6 years.
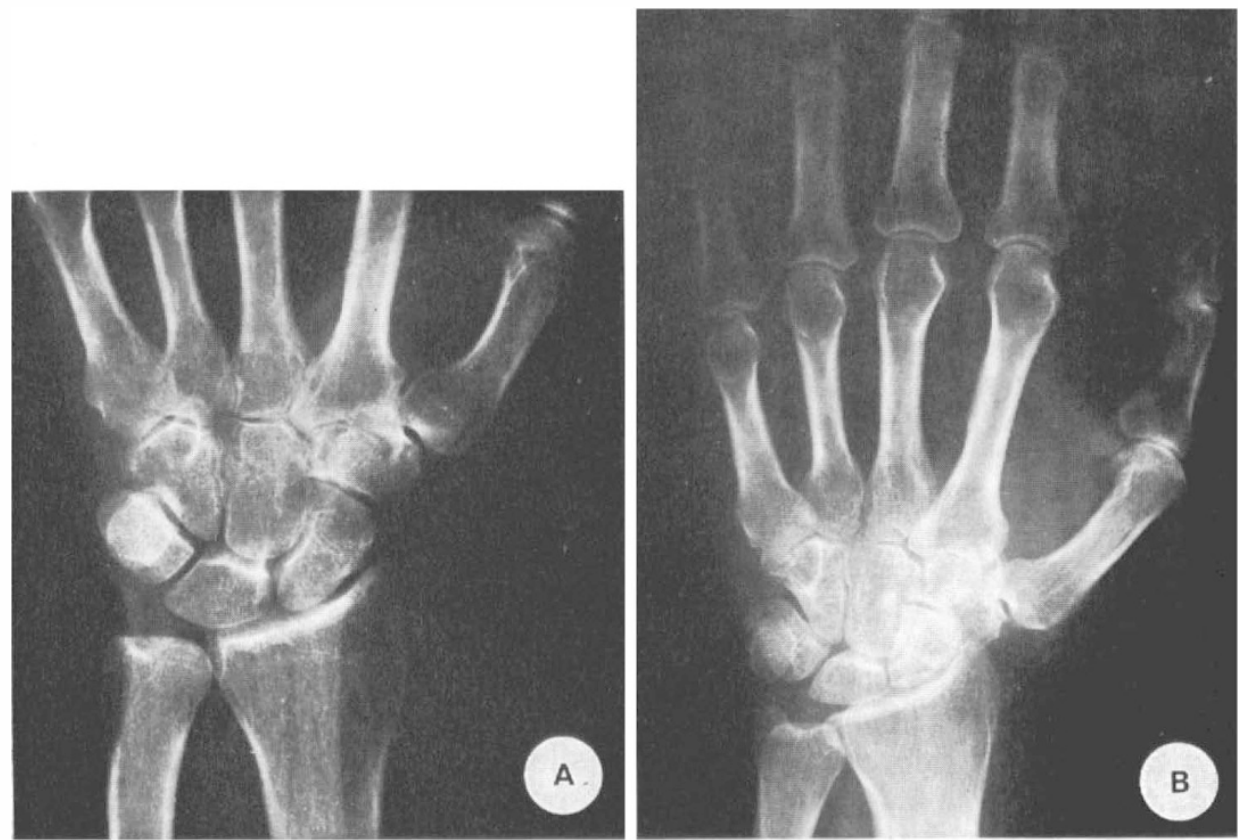

FIG. 3

Loss of trabecular bone in paraplegia. Two cases. A, Note the loss of bone in the distal radius and ulna as well as in the carpus in this paraplegic patient aged 48 who sustained an L4 injury in 1942. B, A similar appearance is apparent in this patient of 45 who was involved in a MVA in 1967 and fractured TI2 resulting in paraplegia. 

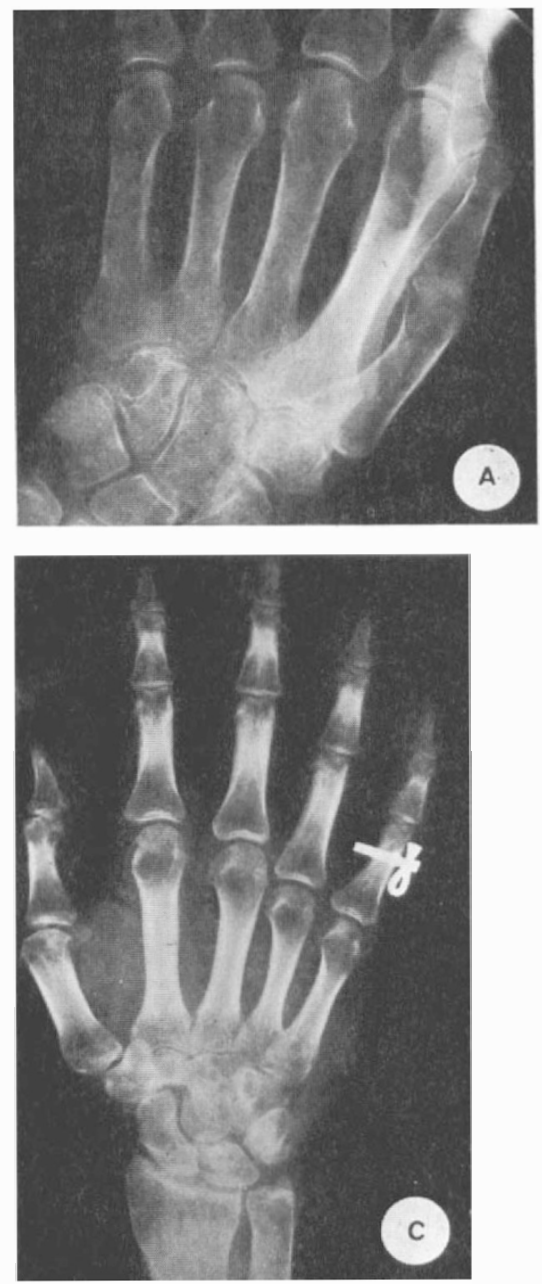

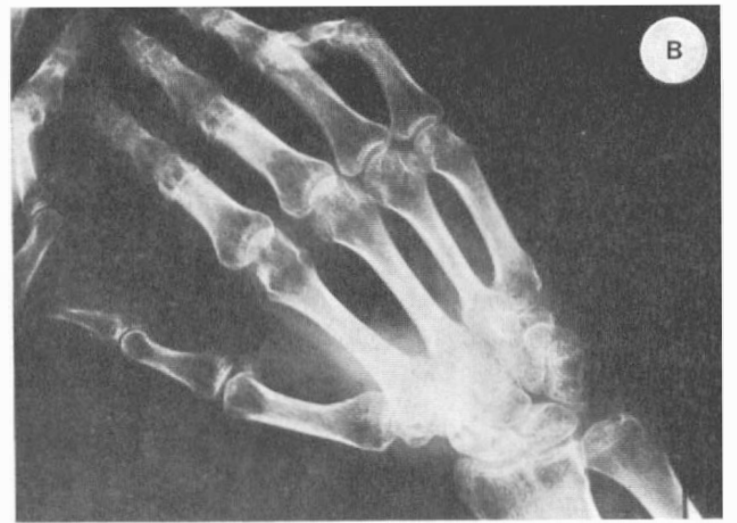

FIG. 4

Generalised osteoporosis; note the lack of trabeculae in the cancellous bone as well as thinning of the cortical bone in paraplegic age 36. B, Cystic osteoporosis; note the localised area without trabeculae (resembling cysts) in this quadriplegic male of 48 . C, Para-articular osteoporesis; note the relative sparing of the midshafts of the metacarpals (quadriplegic aged 25).

trabecular bone radiographically, yet some paraplegic patients showed a similar degree of osteoporosis (fig. I). The extent of demineralisation was not related to the date of injury or to the degree of immobilisation. There were three basic patterns of osteoporosis: generalised (seven patients), juxta-articular (I6 patients), and cystic (two patients) (fig. 4).

\section{Discussion}

These results are of considerable interest, since it has long been held that cortical bone and trabecular bone usually respond similarly although changes in the trabecular bone may be easier to demonstrate radiographically. Our findings of a normal metacarpal index and clavicular index as well as normal bone mineral values using photon absorptiometry tend to confirm a lack of change in cortical bone in patients with spinal cord injury.

Thus there appears to be a different mechanism at work in the type of 
TABLE II

Relationship of osteoporosis in various diseases to clinical parameters

\begin{tabular}{lcccc}
\hline \multicolumn{1}{c}{ Disease } & $\begin{array}{c}\text { Neuronal } \\
\text { damage }\end{array}$ & $\begin{array}{c}\text { Length of } \\
\text { disuse }\end{array}$ & $\begin{array}{c}\text { Vascular } \\
\text { origin }\end{array}$ & $\begin{array}{c}\text { Lack of } \\
\text { movement }\end{array}$ \\
& no & nil & $?$ & no \\
Idiopathic osteoporosis & yes & ? yes & $?$ & ? no \\
SCI-Osteoporosis & yes & ? yes & yes & no \\
Diabetic osteopathy & yes & yes & yes & yes \\
Sudeck's atrophy & no & yes & yes & yes \\
Immobilisation & yes & ? yes & ? yes & ? yes \\
Leprosy & & & & \\
\hline
\end{tabular}

osteoporosis seen in spinal cord injury when compared with so-called idiopathic osteoporosis. In the latter condition there is in all probability a hormonal mechanism at work and involvement of the entire bone matrix occurs. In spinal cord injury there could be a neuronal element involved which may mediate the patchy loss of bone. However, this type of osteoporosis involving mainly the trabecular bone is not confined to patients with central nervous system injury and it has been described in such diverse conditions as diabetic osteoarthropathy (Pogonowska et al., 1967), leprosy (Cave et al., 1965), Sudeck's atrophy (Plews, I956), and in some immobilisation states (Jones, I969) (Table II).

The finding that paraplegic patients also lose trabecular bone in the upper extremity is of extreme interest and has not been described previously (fig. 3). These patients use their arms to propel themselves about in wheelchairs and to lift themselves up as well as in and out of bed and should, if anything, have stronger arms than those of us fortunate enough to be normal. The patients in our series did not appear to develop osteoporosis in proportion to the degree of length of their immobility. Those patients whose injuries occurred 30 to 40 years ago did not show a consistently greater degree of osteoporosis than the patients injured during the past io years. A possible explanation for this loss of trabecular bone in paraplegics is that in spite of the lifting and manoeuvring abilities of their arms, they do not use their lower arms and wrists in the same way as normal people do.

A similar situation occurs in Sudeck's atrophy where loss of bone mineral out of all proportion to the loss of use of the involved limb has been shown to occur (Plews, 1956). The loss of bone mineral in the metaphysis in this latter condition is probably related to the generalised increase in blood flow to the bone. Since the trabecular bone adjacent to the site of the epiphysis has the best blood supply in adult long bones, a localised form of osteoporosis would be expected to occur at this site. It is reasonable to suppose that a similar situation occurs in spinal cord injury.

\section{SUMMARY}

Osteodensitometry performed on 36 patients with paralytic spinal cord injury consistently showed loss of trabecular bone with preservation of cortical bone. There was no relationship between the length or extent of immobility and the degree of demineralisation. These findings suggest that osteoporosis in spinal 
cord injury has a greater association with the osteoporosis that occurs in patients with diabetes, Sudeck's atrophy, and leprosy than with idiopathic osteoporosis. Although the precise pathogenesis is far from clear, these findings tend to implicate alterations in blood flow to the trabecular bone in association with disuse osteoporosis.

\section{RÉSUMÉ}

Trente-six (36) patients avec des lésions de la moelle épinière (22 quadriplegiques et I6 paraplegiques) ont eu des radiographies de la main associées a une mesure de la densité osseuse. L'os corticale de la main, le radius et le cubitus ont étés trouves normaux, mais il éxistait une diminution de la trame osseuse. Il y avait 3 images radiologiques prédominantes osteoporose generalisé juxtaarticulaire et kystique. La cause de cette diminution de la trame osseuse n'est pas connue, quoi qu'on puisse la rattacher aux alterations du courant sanguin.

\section{ZUSAMMENFASSUNG}

Sechsundreissig (36) Patienten mit Rückennarksverletzungen (22 paraplegic und I4 tetraplegic) hatten Röntgenbilder der Hand in Zusamenhang mit Messungen der Knockendichte. Der Kompaktknochen der Hand, des Radius und der Ulna war normal, aber es bestand ein Verlust von Spongiösknocken. Der Knockenverlust ist in 3 verschiedenen Formen erkennbar: allgemein, in der Gelenkumgebung und fleckig. Die Ursache dieses Knockenverlusts ist nicht klar, aber ist vielleicht durch Veränderung der Blutversorgung verursacht.

\section{REFERENCES}

Cave, L., Fustec, R. \& Basset, A. (1965). Radiology of leprosy. Ann. Radiol. Paris, 8, $6 \mathrm{I}-76$.

GriffithS, H. J., D'OrSI, C. J. \& Zimmerman, R. E. (I972). Use of ${ }^{125}$ I photon scanning in the evaluation of bone density in a group of patients with spinal cord injury. Invest. Radiol. 7, I07-I I I.

JoNES, G. (1969). Radiological appearance of disuse osteoporosis. Clin. Radiol. 20, 345-353.

Plews, L. W. (1956). Sudeck's atrophy in the hand. F. Bone foint Surg. 38B, 195-203.

Pogonowska, M. J., Collins, L. S. \& Dobson, M. D. (I967). Diabetic osteopathy. Radiology, 89, 265-27I.

Zimmerman, R. E., Griffiths, H. J. \& D'OrSi, C. J. (I973). Bone mineral measurement by means of photon absorption. Radiology, 106, 56I-564. 